Supporting Information

\title{
High Mobility Organic Field-Effect Transistors from Majority Insulator Blends
}

Michael J. Ford, Ming Wang, Shrayesh N. Patel, Hung Phan, Rachel A. Segalman, Thuc-Quyen Nguyen, Guillermo C. Bazan*

Device Fabrication: Diamond lapping films (from Allied High Tech Products, Inc.) with diamond particle size of $100 \mathrm{~nm}$ were used to introduce "nanogrooves" on the surface of the thermal $\mathrm{SiO}_{2}$ gate dielectric layer ( $\mathrm{Si}$ wafers from University Wafer). All substrates scratched were 4-inch wafers cut in half. The scratching method involved placing the dielectric surface upon a wet nanoparticle film and sliding the wafer unidirectionally for a total scratching distance of $\sim 1.5 \mathrm{~m}$ (16 times across the $\mathrm{SiO}_{2}$ surface). The adhesion between deionized water, the substrate, and the lapping film along with a gentle applied pressure facilitated nanogroove formation (Figure S1). Source and drain contacts $(5 \mathrm{~nm} \mathrm{Ni} / 50 \mathrm{~nm} \mathrm{Au})$ were deposited using a standard two-step photolithography. Before polymer deposition, the substrates were cleaned by sonication in acetone and isopropanol for 3 minutes each, and were then dried in an oven under ambient atmosphere at $120{ }^{\circ} \mathrm{C}$ for 10 minutes. The substrates were treated with $\mathrm{UV}-\mathrm{O}_{3}$ for 15 minutes and submerged in dilute $\mathrm{Ni}$ etchant to etch the Ni adhesion layer. Subsequently, the substrates were dried in an oven oven under ambient atmosphere at $120{ }^{\circ} \mathrm{C}$ for 10 minutes, treated again with $\mathrm{UV}-\mathrm{O}_{3}$ for 15 minutes, and then passivated by using decyltrichlorosilane (from Gelest Chemicals) from a 1 vol\% solution in toluene at $80{ }^{\circ} \mathrm{C}$ for 25 minutes. The substrates were then rinsed and sonicated in toluene and dried under nitrogen flow. Blend films were deposited immediately after. The blend concentration was $5 \mathrm{mg} / \mathrm{mL}$ with respect to the total PS + PCDTPT content. Stock solutions of PS (Sigma-Aldrich, weight average molecular weight $=35,000 \mathrm{~g} / \mathrm{mol}$ ) and PCDTPT (number average molecular weight $=50,976$, weight average molecular weight $=162,135, \mathrm{PDI}=3.18$ ) were dissolved in chlorobenzene and mixed by volume to obtain the corresponding blend weight ratio (e.g., $500 \mu \mathrm{L}$ of $5 \mathrm{mg} / \mathrm{mL}$ of PCDTPT mixed with $500 \mu \mathrm{L}$ of $5 \mathrm{mg} / \mathrm{mL}$ PS to form a $50 \mathrm{wt}$. \% solution.) The molecular weight of PCDTPT was determined using a polystyrene calibrated gel permeation chromatography with Waters 2410 Differential Refract Meter and Waters 2998 Photodiode Array detectors with 0.25 vol. \% triethylamine in chloroform as the eluent.

A blade-coat and stage was built using a LTA-HS actuator and integrated CONEX-CC controller. The blade material, blade angle, blade height and coating speed can be modified using this setup. The motor controls the motion of the blade in the lateral direction while a micrometer is used to control the blade height relative to a hot plate, which is used as the surface for the substrate. The blade angle was set to $60^{\circ}$ relative to the plane of the substrate. In this case, the blades used were glass microscope slides, which were cleaned by piranha solution. The substrate was coated by injecting $8 \mu \mathrm{L}$ of solution in between a $\sim 100 \mu \mathrm{m}$ channel formed between the blade and the substrate. This height was set by lowering the glass blade to the substrate until the substrate could not be moved; then, the micrometer was zeroed and raised $100 \mu \mathrm{m}$. Other conditions (speed and temperature) are specified within the text for the different conditions. Thicknesses for Condition 2 were measured to be $130 \pm 7 \mathrm{~nm}$ for $100 \mathrm{wt}$. $\%$ PCDTPT, $56 \pm 11 \mathrm{~nm}$ for $75 \mathrm{wt}$ \% PCDTPT, $57 \pm 16 \mathrm{~nm}$ for $50 \mathrm{wt}$. \% PCDTPT, and $38 \pm 16 \mathrm{~nm}$ for $25 \mathrm{wt}$ \% PCDTPT. Surface roughness contributed to higher relative variation in sample thickness for samples with 
greater PS content. Speed and temperature were modified simultaneously to generate continuous and smooth films. At too low of a temperature device performance may be reduced while too high of a temperature produced rough films undesirable for morphological characterization. Bottom gate, bottom contact field-effect transistors were fabricated for blend composition ratios of 10wt. \%, 25wt. \%, 50wt. \%, 75wt. \%, 90wt. \%, and 100wt. \% PCDTPT. Film formation at compositions as low as $3 \mathrm{wt}$. \% was attempted, but film coverage was poor likely due to unfavourable wetting of the majority PS solution. The results of one device can be seen in Figure S12. The blend solutions were made from parent solutions of pure PCDTPT and PS. Devices were annealed for $200{ }^{\circ} \mathrm{C}$ for 8 minutes. The final device architecture (from bottom to top) for these bottom gate, bottom contact field-effect transistors was $\mathrm{Si}(500 \mu \mathrm{m}) / \mathrm{DTS}$-treated $\mathrm{SiO}_{2}(300 \mathrm{~nm}) / \mathrm{Ni}(5 \mathrm{~nm}) / \mathrm{Au}(50 \mathrm{~nm}) / \mathrm{blend}$ layer.

Device Characterization: The mobility of blend devices were obtained by fitting the following equation to the saturation regime transfer characteristics: $\mathrm{I}_{\mathrm{DS}}=(\mathrm{W} / 2 \mathrm{~L}) \mathrm{C}_{\mathrm{i}} \mu\left(\mathrm{V}_{\mathrm{GS}}-\mathrm{V}_{\mathrm{th}}\right)^{2}$, where $\mathrm{W}$ is the channel width $(1$ or 2 $\mathrm{mm}$ ), $\mathrm{L}$ is the channel length ( 80 or $160 \mu \mathrm{m}), \mathrm{C}_{\mathrm{i}}$ is the gate dielectric layer capacitance per unit area (10 and 11.5 $\mathrm{nF} / \mathrm{cm}^{2}$ for normal and nanogrooved substrates), ${ }^{[12,13,33]} \mathrm{V}_{\mathrm{GS}}$ is the gate voltage, $\mathrm{V}_{\mathrm{th}}$ is the threshold voltage, and $\mathrm{I}_{\mathrm{DS}}$ is the source-drain voltage. Devices were measured under nitrogen in a glovebox using a Signatone 1160 probe station and Keithley 4200 semiconductor parametric analyzer. Mobility values calculated from a gate voltage range of -20 $\mathrm{V}$ to $-40 \mathrm{~V}$ at a source-drain voltage of $-80 \mathrm{~V}$. Micrographs were obtained using an Olympus MX51 microscope at $31.5 x$ magnification with differential interference contrast. Tapping-mode atomic force microscopy (AFM) images were obtained in air using an Innova AFM. Differential scanning calorimetry (DSC) was determined by a TA Instruments DSC (Model Q-20) with about $3 \mathrm{mg}$ polymer samples at a rate of $10{ }^{\circ} \mathrm{C} / \mathrm{min}$ in the temperature range of 30 to $330{ }^{\circ} \mathrm{C}$. Grazing incidence wide angle X-ray scattering (GIWAXS) measurements were performed at beamline 11-3 at the Stanford Synchrotron Radiation Lightsource (SSRL) with an X-ray wavelength of $0.9744 \AA$ at a $400 \mathrm{~mm}$ sample detector distance. Samples were scanned in a He environment at an incident angle of $0.12^{\circ}$. The measurements were calibrated using an LaB6 standard. Profilometry measurements were done with a Ambios XP100 profilometer. 


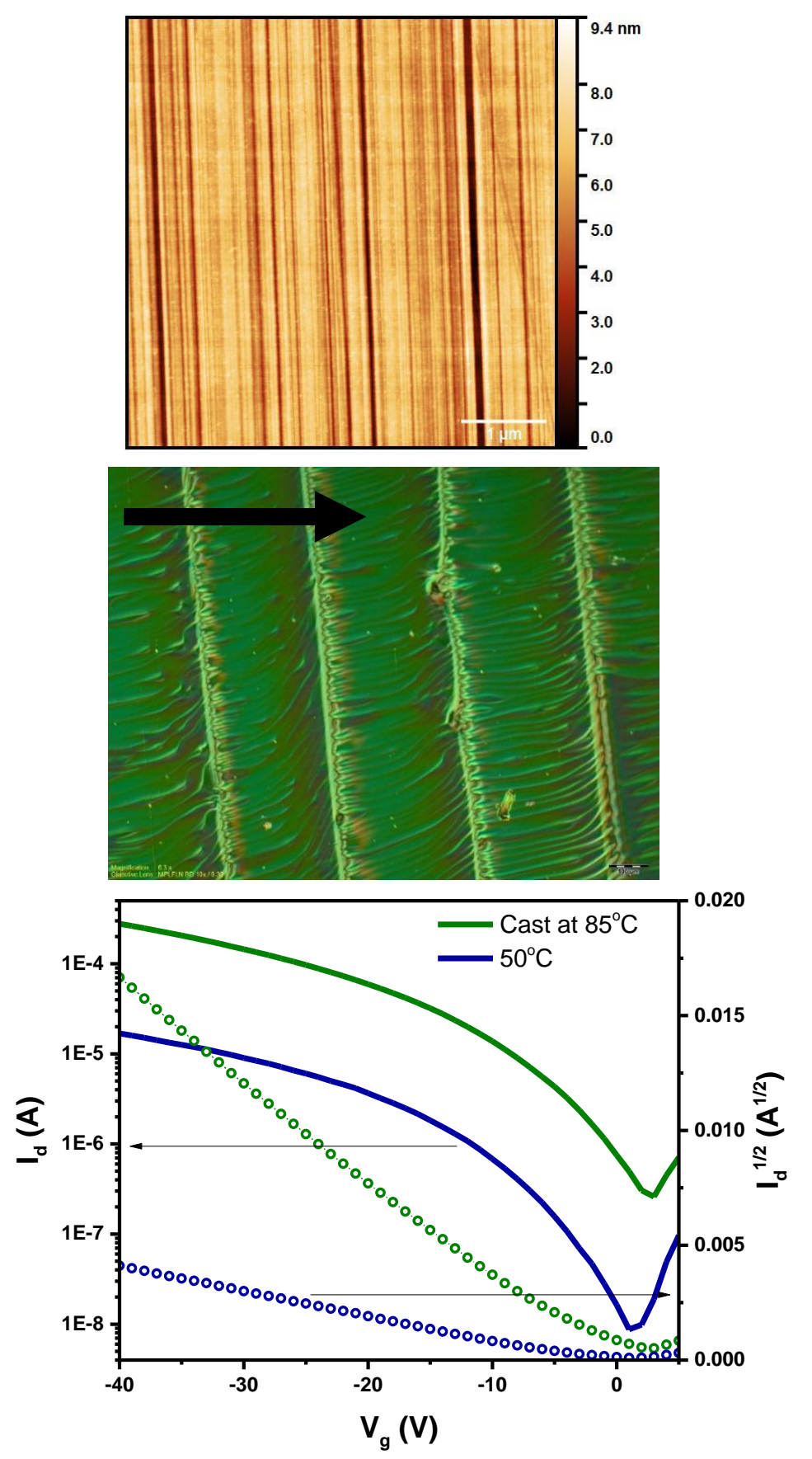

Figure S1. (Top) AFM image of nanogrooved substrate. (Middle) Microscopy image of PCDTPT cast at $0.3 \mathrm{~mm} / \mathrm{s}$ at $100^{\circ} \mathrm{C}$. The scale bar in the bottom right corner represents $100 \mu \mathrm{m}$. The blade-coating direction has been indicated with an arrow. Features are due to drying effects. Casting at slow blade speed and high temperatures result in thick, non-uniform films. (Bottom) Transfer characteristics for devices cast at $0.8 \mathrm{~mm} / \mathrm{s}$ and at two different temperatures. Casting too quickly without increasing evaporation rate can impact device performance. 



Figure S2. Representative transfer and output curves for the various blend compositions cast at $0.1 \mathrm{~mm} / \mathrm{s}$ and $50^{\circ} \mathrm{C}$.
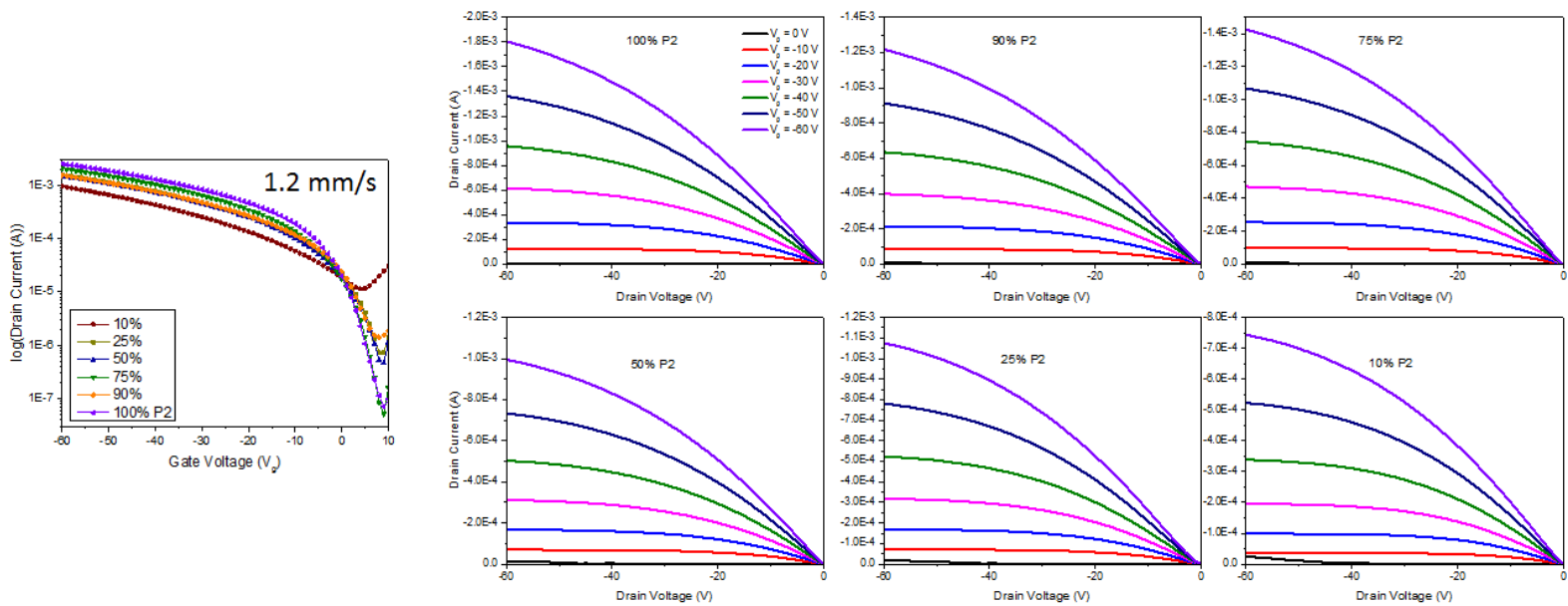

Figure S3. Representative transfer and output curves for the various blend compositions cast at $1.2 \mathrm{~mm} / \mathrm{s}$ and $100^{\circ} \mathrm{C}$. 


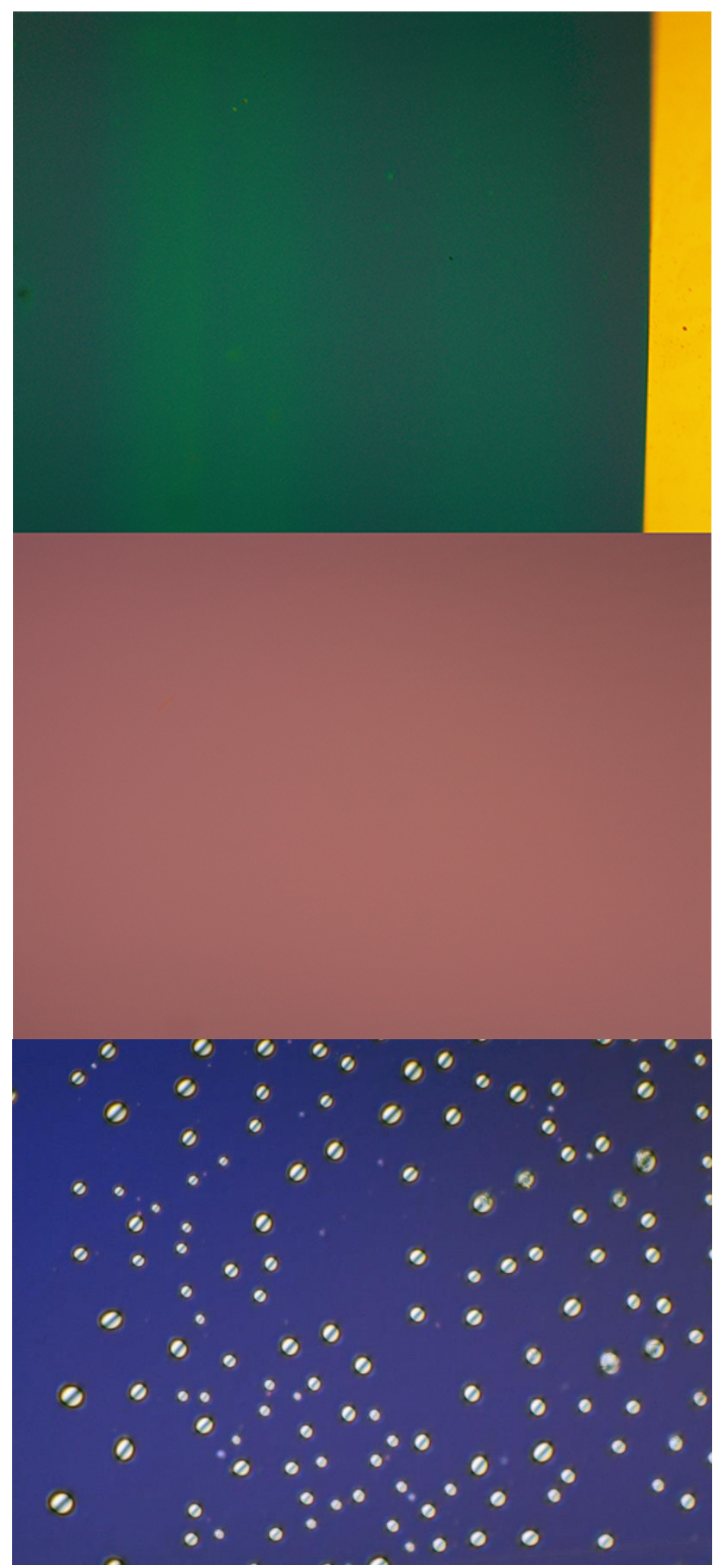

Figure S4. Optical micrographs of pristine PCDTPT (top), a bare substrate (middle), and pristine polystyrene (bottom) at 31.5x magnification. The optical image sizes are $280 \mu \mathrm{m}$ wide. The gold feature on the right of the top image is the Au electrode. 


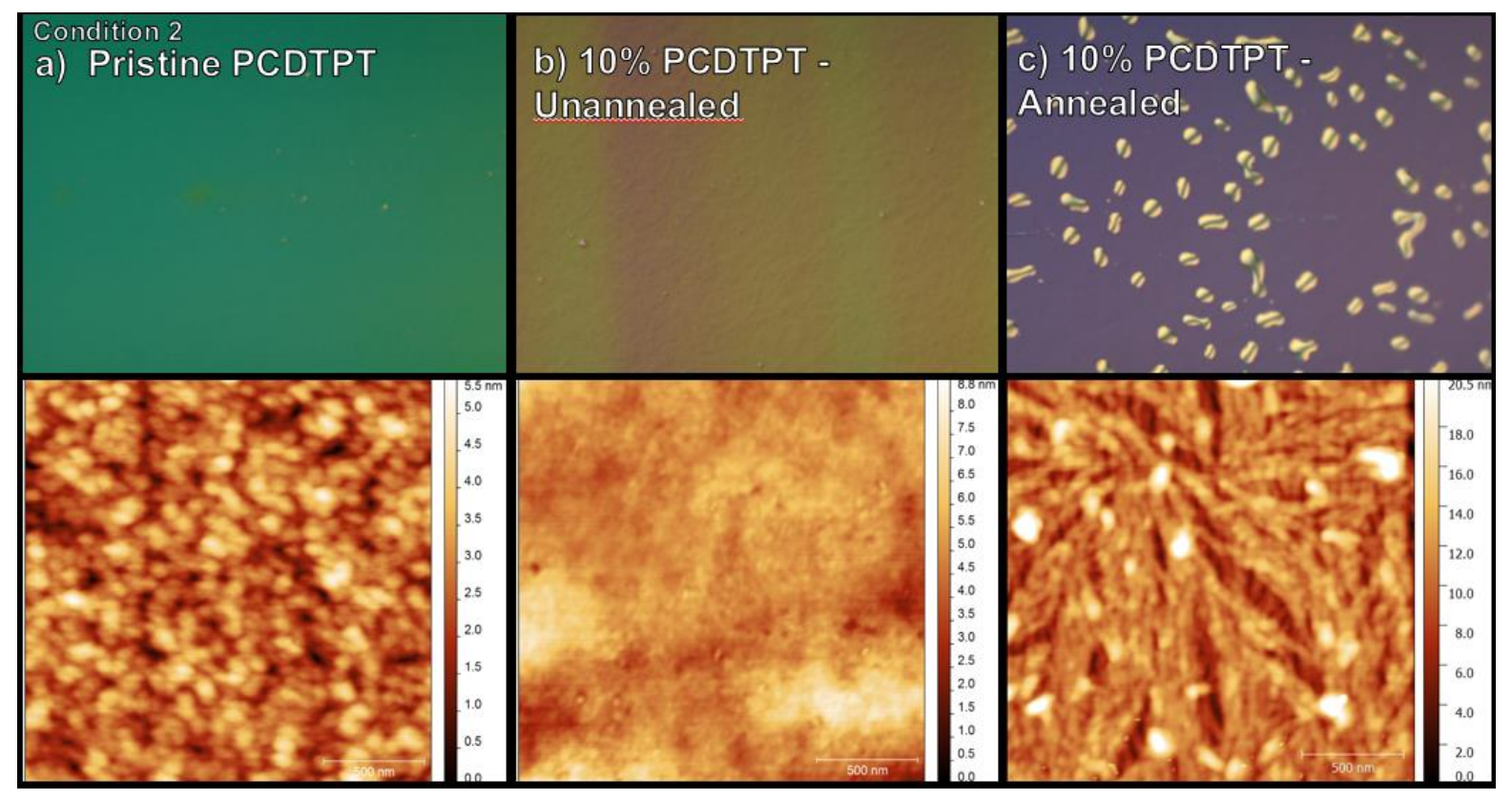

Figure S5. For Condition 2, optical micrographs and AFM images of a) pristine PCDTPT, b) 10\% PCDTPT films before annealing and c) $10 \%$ PCDTPT after annealing at $200^{\circ} \mathrm{C}$. Polystyrene dewetting occurs and causes a change in color of the thin film. Optical micrographs are $280 \mu \mathrm{m}$ in width. AFM images are $2 \mu \mathrm{m}$ in width. Buried fiber formation in the $10 \%$ PCDTPT is visible only after annealing. Comparison of a) and b) also provides further evidence for PS favouring the top surface.


parallel and perpendicular mobility in substrates with nanogrooves (left) and without nanogrooves (right). Anisotropic mobility exists for devices cast on substrates with nanogrooves. Devices were cast under Condition 1. The mobility parallel to the blade-coating and groove direction is $2.5 \mathrm{~cm}^{2} \mathrm{~V}^{-1} \mathrm{~s}^{-1}$ in this case. For the perpendicular direction, mobility is at $0.22 \mathrm{~cm}^{2} \mathrm{~V}^{-1} \mathrm{~s}^{-1}$ in this case. Without nanogrooves, the mobility was measured to be 0.29 $\mathrm{cm}^{2} \mathrm{~V}^{-1} \mathrm{~s}^{-1}$ in the parallel direction and $0.26 \mathrm{~cm}^{2} \mathrm{~V}^{-1} \mathrm{~s}^{-1}$ in the perpendicular direction. There is no significant difference in this case. 


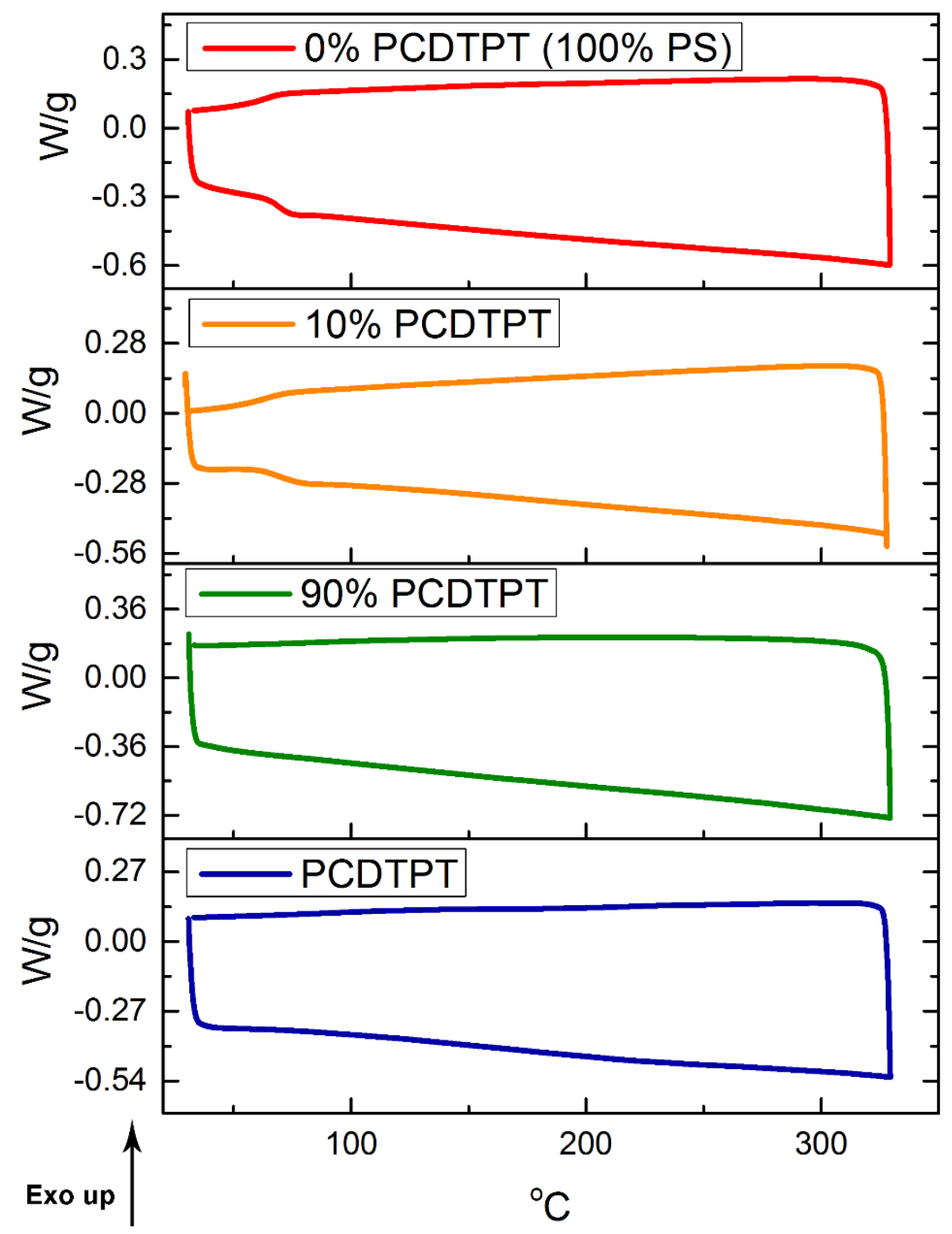

Figure S7. Differential scanning calorimetry (DSC) was used to investigate thermal transitions in the polymer blends and pristine materials. DSC curves can be found in the Supporting Information Polymer blend solutions of 90 wt.\% and $10 \mathrm{wt} . \%$ PCDTPT were deposited directly into the DSC hermetic pans, and the solvent was allowed to evaporate. The glass transition temperature ranges from $64.78-73.77^{\circ} \mathrm{C}$ with a midpoint of $68.79^{\circ} \mathrm{C}$ for pristine PS and ranges from $62.08-75.34^{\circ} \mathrm{C}$ with a midpoint of $67.64^{\circ} \mathrm{C}$ for $10 \%$ PCDTPT. No thermal transitions were observed for $90 \%$ PCDTPT and pristine PCDTPT. Binary blends of polymers that are completely miscible should demonstrate glass transition temperatures independent of composition. ${ }^{[1]}$ It could be the case that the mass of PS in 90\% PCDTPT is just too small for the glass transition to be observed or that the two components are partially miscible. It's important to note that DSC measurements are done with bulk material (rather than a thin film) and in a hermetic pan (rather than on a DTS-treated $\mathrm{SiO}_{2}$ substrate.) 


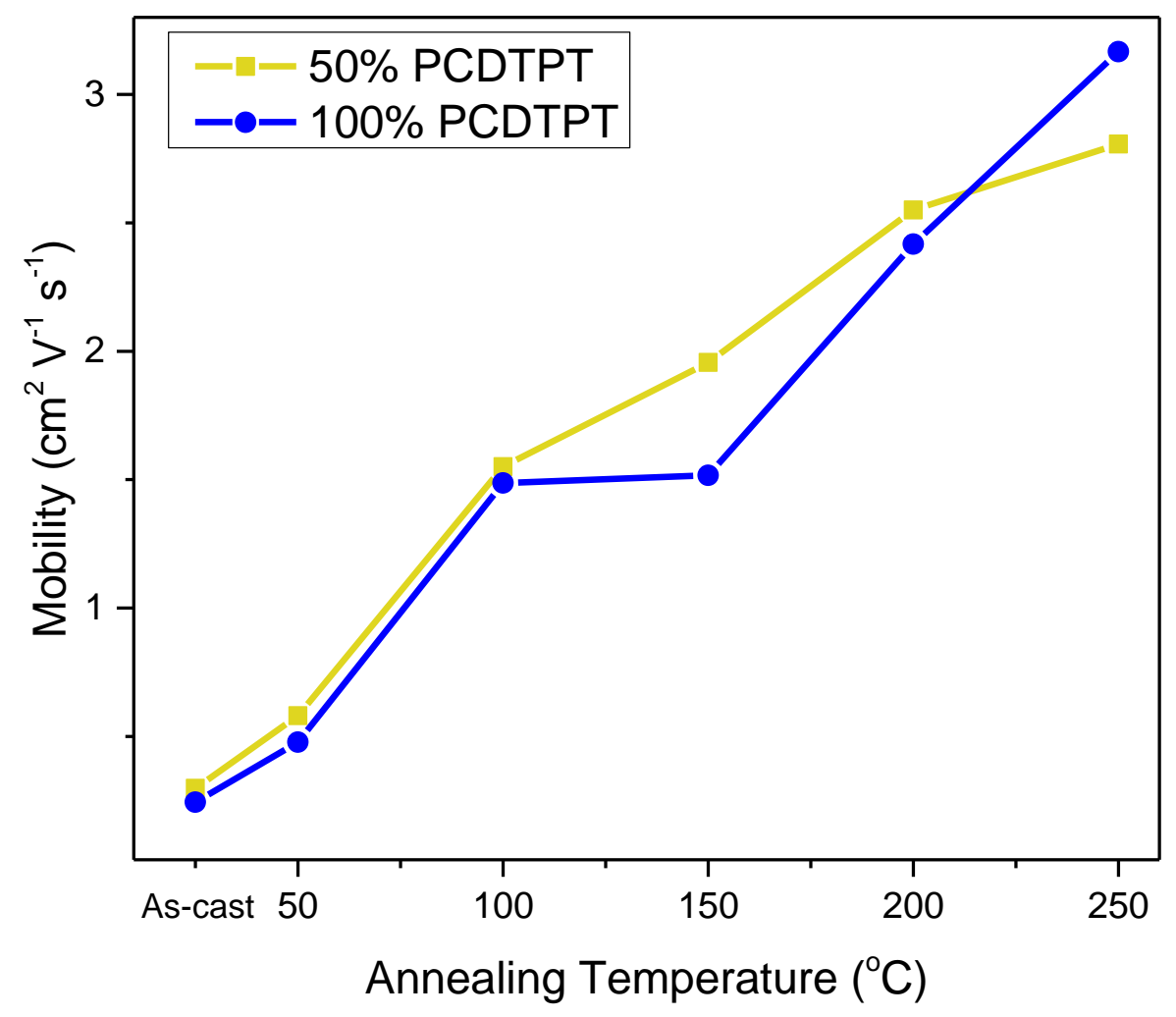

Figure S8. Average of three devices cast at $0.1 \mathrm{~mm} / \mathrm{s}$ and $50^{\circ} \mathrm{C}$ tested for mobility dependence of mobility on annealing temperature for $50 \%$ and $100 \%$ PCDTPT

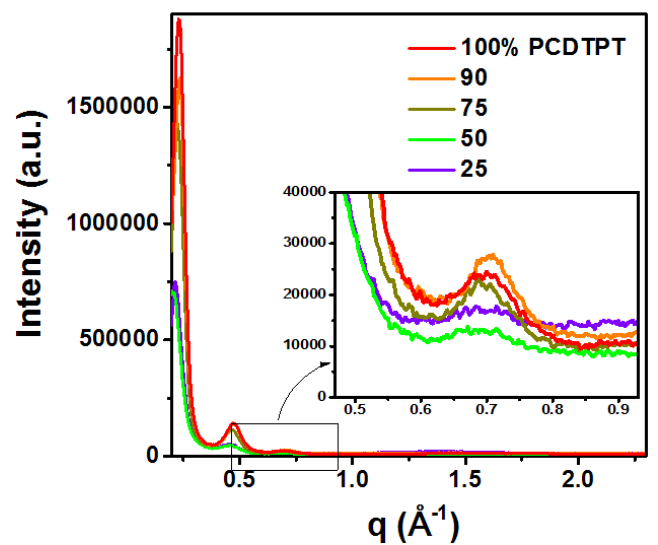

Figure S9: Out-of-plane GIWAXS of PCDTPT blend films. 
Double-Slope and Bias Stress Effects: One issue that has been a topic of debate among the OFET community is the double slope behaviour of many high mobility systems. This issue specifically relates to the double slope that occurs when fitting the dependence of the square root of the drain current as a function of gate voltage to the saturation mobility regime equation. The saturation mobility regime equation should result in constant mobility regardless of gate voltage when the device is on. However, non-idealities are often observed whereby the mobility can be extracted from either a higher mobility regime or a lower mobility regime (Figure S8). Many argue for conservative estimates so as to not convolute the actual charge carrying properties. ${ }^{[2]}$ For PCDTPT devices, the double slope is not always observed (Figure S6, e.g.); therefore, in this report, mobility has been reported only for devices that exhibited no or minimal double slope behaviour. If minimal double slope behaviour was observed, for consistency, estimates were in the low mobility (higher $\mathrm{V}_{\mathrm{g}}$ ) regime.

Bias stress effects have also been an issue for these devices. A recent report outlines this behaviour ${ }^{[3]}$, and so it will only be described cursorily here. When scanning the gate voltage of the device while applying a constant drain voltage, the drain current at high negative gate voltages increases while the current at positive gate voltages decreases. The devices were scanned multiple times (applying bias in the forward and reverse direction for ca. 3-5 min.) until a steady-state current was achieved. The result was almost invariably double slope behaviour and a marked improvement in the charge carrier mobility at low gate voltage. However, as reported, the resulting higher mobility regime is not stable and can result in a wide range of mobilities (Figure S9). For these reasons, the mobility for devices that underwent bias stressing has not been reported; only the first scan is used to calculate the mobility reported in this submission. Regardless of whether this is more representative of the device mobility or not, it is consistent and allows for comparison between the blends.

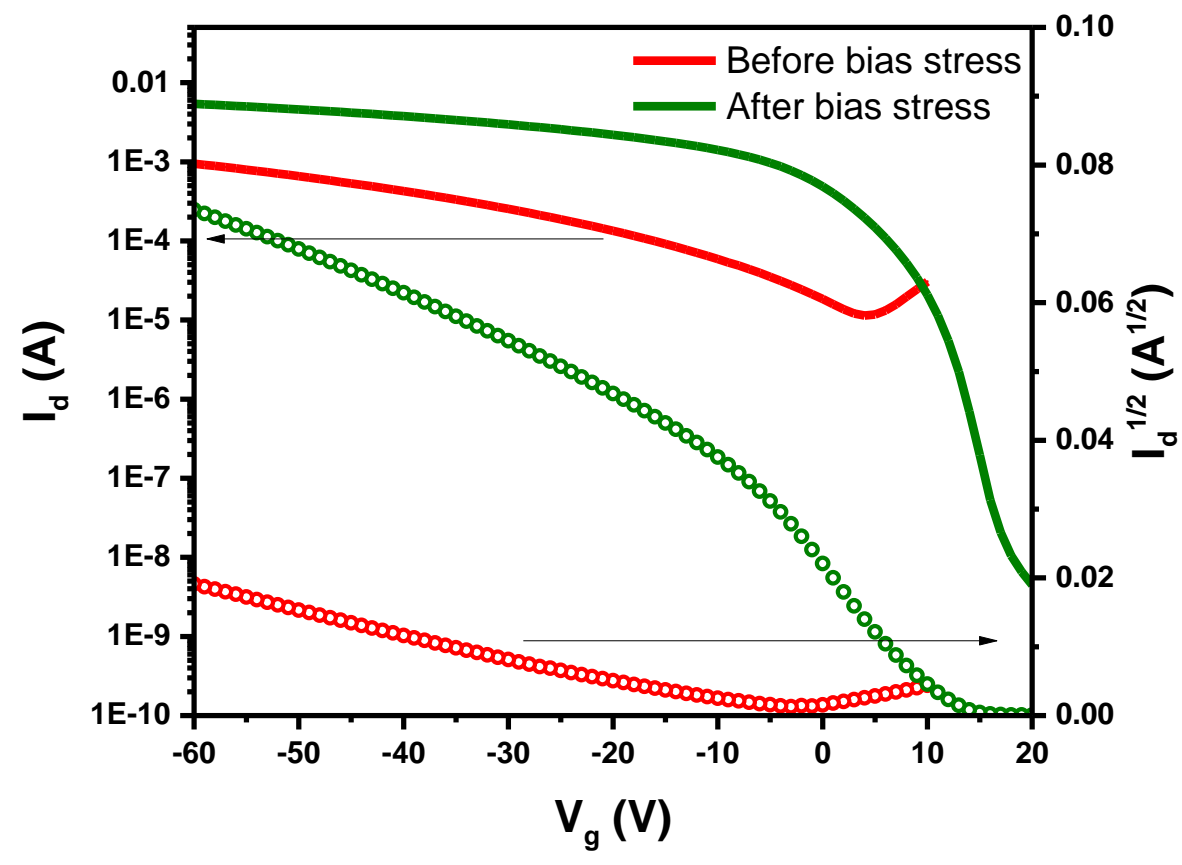

Figure S10. Stressing behavior of a PCDTPT device. If fit in a gate voltage regime in the range of 10 to $0 \mathrm{~V}$, the mobility can be estimated as $58 \mathrm{~cm}^{2} \mathrm{~V}^{-1} \mathrm{~s}^{-1}$. In the lower mobility regime, the mobility is $8 \mathrm{~cm}^{2} \mathrm{~V}^{-1} \mathrm{~s}^{-1}$. For comparison, a more ideal transfer curve is shown. The mobility for this device is $6 \mathrm{~cm}^{2} \mathrm{~V}^{-1} \mathrm{~s}^{-1}$. 

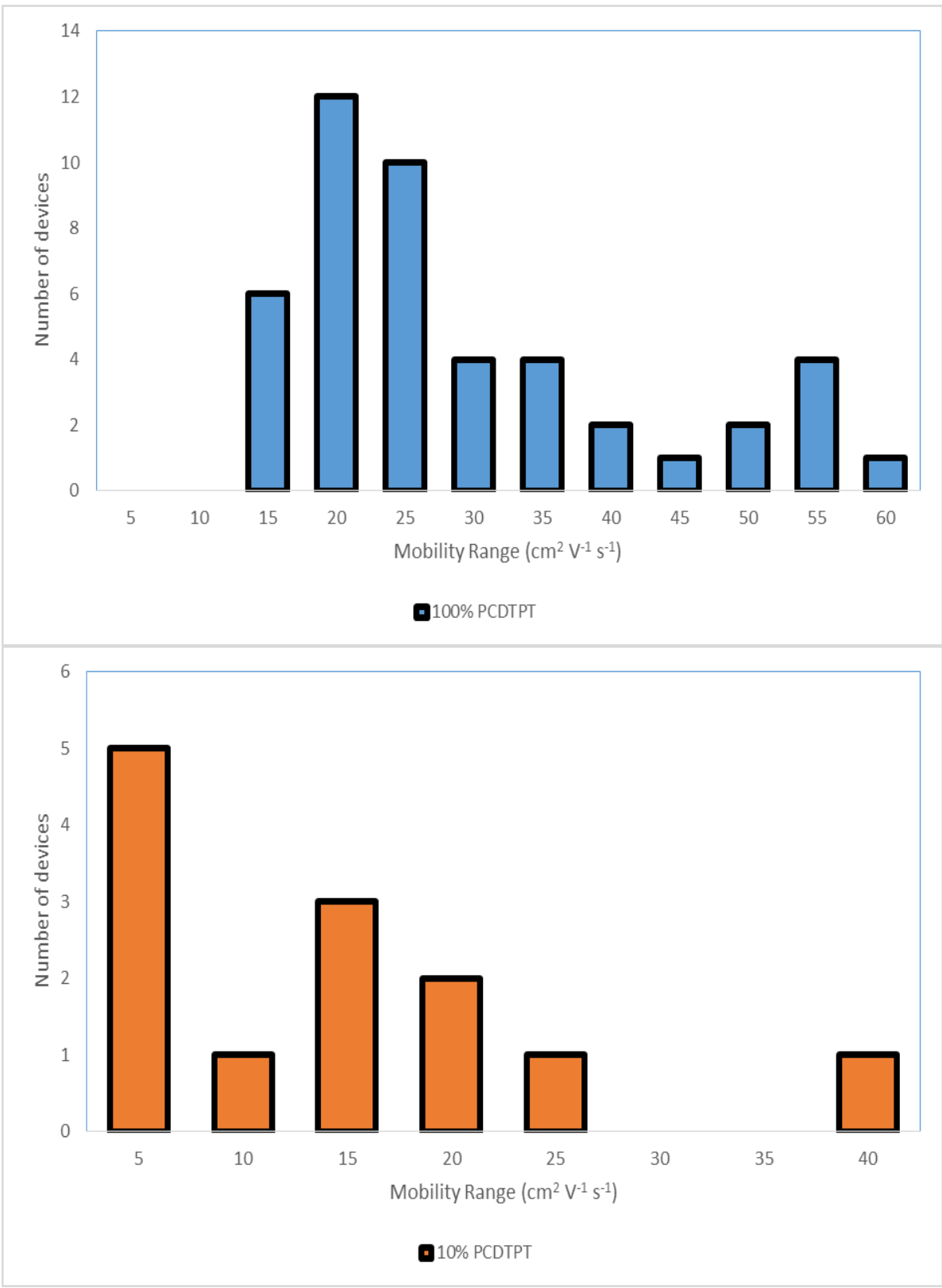

Figure S11. Various mobilities observed in the high mobility regime of the observed double slope after bias stress. The mobilities shown are for 100\% PCDTPT and 10\% PCDTPT. The $\mathrm{x}$-axis represents a range of mobilities starting from the previous indicated value up to the labeled value (e.g., for the label 15, these mobilities were between 10.115.0). 


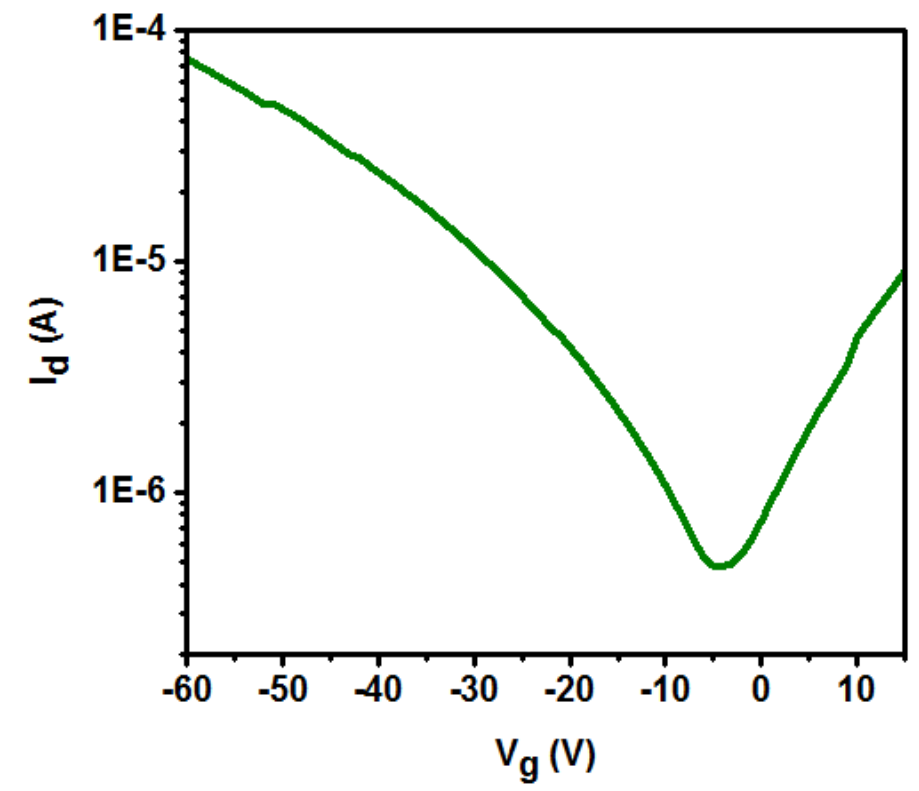

Figure S12. Seeking a threshold limit of semiconductor content, we attempted to cast devices from 3 wt. \% PCDTPT. This resulted in poor substrate coverage, likely due to unfavorable wetting by PS. Still, some devices were completely covered and the average mobility of those devices cast at Condition 1 on nanogrooved substrates was $0.75 \pm 0.06 \mathrm{~cm}^{2} \mathrm{~V}^{-1} \mathrm{~s}^{-1}$. A 3 wt. \% device transfer curve is shown above. 
Table S1. Mobility as a function of composition for devices cast under Condition 1.

\begin{tabular}{|c|c|c|c|c|c|}
\hline $\begin{array}{c}10 \\
\text { wt. } \%\end{array}$ & 25 wt. $\%$ & 50 wt. $\%$ & 75 wt. $\%$ & 90 wt. $\%$ & $\begin{array}{l}100 \text { wt. } \% \\
\text { PCDTPT }\end{array}$ \\
\hline \multicolumn{6}{|c|}{ Parallel Mobility $\left[\mathrm{cm}^{2} \mathrm{~V}^{-1} \mathrm{~s}^{-1}\right]$} \\
\hline 2.4 & 2.4 & 2.9 & 2.6 & 2.2 & 2.4 \\
\hline 2.0 & 4.4 & 2.7 & 2.8 & 2.0 & 2.8 \\
\hline 2.4 & 1.8 & 1.7 & 2.6 & 2.2 & 2.2 \\
\hline 2.6 & 4.2 & 2.0 & 2.4 & 2.6 & 2.4 \\
\hline 1.2 & 3.6 & 1.9 & 2.8 & 2.6 & 2.0 \\
\hline 1.0 & 3.8 & 2.2 & 2.6 & 2.8 & 2.4 \\
\hline 2.8 & 5.2 & 2.0 & 2.4 & 2.6 & 2.5 \\
\hline 1.4 & 1.3 & 1.9 & 2.2 & 2.8 & 2.0 \\
\hline 1.9 & 1.2 & 2.7 & 2.4 & 2.6 & 3.0 \\
\hline 1.6 & 1.2 & 3.0 & 2.5 & 3.1 & 2.3 \\
\hline 1.6 & 1.7 & 3.3 & 2.8 & 2.9 & 3.0 \\
\hline 1.9 & 2.8 & 2.4 & 2.6 & 2.6 & 2.5 \\
\hline \multicolumn{6}{|c|}{ Perpendicular Mobility $\left[\mathrm{cm}^{2} \mathrm{~V}^{-1} \mathrm{~s}^{-1}\right]$} \\
\hline 0.16 & 0.22 & 0.19 & 0.22 & 0.18 & 0.20 \\
\hline 0.24 & 0.12 & 0.20 & 0.20 & 0.24 & 0.22 \\
\hline 0.20 & 0.22 & 0.23 & 0.26 & 0.28 & 0.24 \\
\hline 0.20 & 0.19 & 0.21 & 0.23 & 0.23 & 0.22 \\
\hline \multicolumn{6}{|c|}{ Anisotropy $\left(\mu_{\text {para }} / \mu_{\text {perp }}\right)$} \\
\hline 9.5 & 14.7 & 11.4 & 11.3 & 11.3 & 11.4 \\
\hline
\end{tabular}


Table S2. Mobility as a function of composition for devices cast under Condition 2.

\begin{tabular}{|c|c|c|c|c|c|}
\hline $\begin{array}{c}10 \\
\text { wt. } \%\end{array}$ & 25 wt. $\%$ & 50 wt. $\%$ & 75 wt. $\%$ & 90 wt. $\%$ & $\begin{array}{l}100 \text { wt. \% } \\
\text { PCDTPT }\end{array}$ \\
\hline \multicolumn{6}{|c|}{ Parallel Mobility $\left[\mathrm{cm}^{2} \mathrm{~V}^{-1} \mathrm{~s}^{-1}\right]$} \\
\hline 2.2 & 3.9 & 3.6 & 5.6 & 5.6 & 5.8 \\
\hline 2.1 & 4.3 & 3.1 & 5.8 & 5.2 & 4.7 \\
\hline 2.4 & 2.7 & 3.5 & 5.5 & 5.3 & 5.4 \\
\hline 2.1 & 4.5 & 4.5 & 6.1 & 4.4 & 5.7 \\
\hline 2.5 & 3.0 & 4.4 & 6.9 & 4.9 & 4.8 \\
\hline 2.7 & 3.3 & 4.3 & 6.4 & 4.3 & 6.3 \\
\hline 3.1 & 4.7 & 4.5 & 6.2 & 5.1 & 7.1 \\
\hline 2.9 & 5.2 & 4.0 & 4.8 & 4.5 & 7.4 \\
\hline 3.8 & 4.9 & 4.4 & 5.6 & 5.0 & 7.0 \\
\hline 3.6 & 5.8 & 5.3 & 6.1 & 5.6 & 7.0 \\
\hline 2.7 & 4.2 & 4.2 & 5.9 & 5.0 & 6.1 \\
\hline \multicolumn{6}{|c|}{ Perpendicular Mobility $\left[\mathrm{cm}^{2} \mathrm{~V}^{-1} \mathrm{~s}^{-1}\right]$} \\
\hline 0.24 & 0.41 & 0.54 & 0.55 & 0.54 & 0.48 \\
\hline 0.24 & 0.39 & 0.45 & 0.52 & 0.53 & 0.55 \\
\hline 0.21 & 0.34 & 0.49 & 0.53 & 0.59 & 0.68 \\
\hline 0.23 & 0.38 & 0.49 & 0.54 & 0.56 & 0.57 \\
\hline \multicolumn{6}{|c|}{ Anisotropy $\left(\mu_{\text {para }} / \mu_{\text {perp }}\right)$} \\
\hline 11.9 & 11.1 & 8.4 & 11.0 & 9.0 & 10.7 \\
\hline
\end{tabular}

\section{References:}

1. Brostow, W.; Chiu, R.; Kalogeras, I. M.; Vassilikou-Dova, A. Prediction Of Glass Transition Temperatures: Binary Blends and Copolymers. Mater. Lett. 2008, 62, 3152-3155

2. Sirringhaus, H. 25th Anniversary Article: Organic Field-Effect Transistors: The Path Beyond Amorphous Silicon. Adv. Mater. 2014, 26, 1319-1335.

3. Phan, H.; Wang, M.; Bazan, G. C.; Nguyen, T.-Q. Electrical Instability Induced By Electron Trapping in Low-Bandgap Donor-Acceptor Polymer Field-Effect Transistors.Adv. Mater. 2015, 27, 7004-7009. 